\title{
A Dual Ensemble Agroclimate Modelling Procedure to Assess Climate Change Impacts on Sugarcane Production in Australia
}

\author{
Yvette Everingham $^{1,2}$, Geoff Inman-Bamber ${ }^{1}$, Justin Sexton ${ }^{1,2^{*}}$, Chris Stokes ${ }^{3}$ \\ ${ }^{1}$ College of Science, Technology and Engineering, James Cook University, Townsville, Australia \\ ${ }^{2}$ Centre for Tropical Environmental \& Sustainable Science, Townsville, Australia \\ ${ }^{3}$ Plant Industries, CSIRO, ATSIP, James Cook University, Townsville, Australia \\ Email: *justin.sexton@my.jcu.edu.au
}

Received 23 June 2015; accepted 24 August 2015; published 27 August 2015

Copyright (C) 2015 by authors and Scientific Research Publishing Inc.

This work is licensed under the Creative Commons Attribution International License (CC BY).

http://creativecommons.org/licenses/by/4.0/

c) (i) Open Access

\section{Abstract}

Climate is a key driver of sugarcane production and all its by-products. Consequently, it is important to understand how climate change will influence sugarcane crop productivity. Ensembles from a crop model and climate projections form part of the dual ensemble methodology to assess climate change impacts on sugarcane productivity for three major sugarcane-growing regions in Australia-Burdekin, Mackay and New South Wales (NSW). Different parameterisations of a crop model injected with climate outputs from eleven statistically downscaled general circulation models (GCM) were used to estimate regionally averaged sugarcane yields for the base period 1971 to 2000 . The forward stagewise algorithm selected crop model parameterisations that best explained the observed yields. Leave-one-out cross validation assessed the predictive capability of the equally weighted crop ensemble members characterised by the selected crop model parameterizations. A Monte Carlo permutation testing procedure was employed to measure the significance of the predictive correlations. The predictive correlations between historical yields and simulated historical yields for the Burdekin, Mackay and NSW were $0.69(p=0.030), 0.83(p<0.001)$ and $0.70(p=0.034)$, respectively. Simulations were run based on GCM projections for 2046 to 2065 for a low (B1) and a high (A2) emission scenario, with and without elevated $\mathrm{CO}_{2}$ levels. We found it was plausible for industry to consider an increase in yields to all three regions under the $\mathrm{B} 1$ scenario and highly plausible for $\mathrm{NSW}$ under the $\mathrm{A2}$ scenario. Higher $\mathrm{CO}_{2}$ levels resulted in lower demand of water for the crop, particularly in the Burdekin region and suggested that industry could expand into regions currently considered as marginal owing to the benefits of increased transpiration efficiency that are associated with increased $\mathrm{CO}_{2}$. Although this study favoured neutral or positive impacts on sugarcane production, industry should not overlook negative impacts when developing a risk management framework in response to a changing climate.

${ }^{*}$ Corresponding author.

How to cite this paper: Everingham, Y., Inman-Bamber, G., Sexton, J. and Stokes, C. (2015) A Dual Ensemble Agroclimate Modelling Procedure to Assess Climate Change Impacts on Sugarcane Production in Australia. Agricultural Sciences, 6, 870888. http://dx.doi.org/10.4236/as.2015.68084 


\section{Keywords}

\section{Agriculture, Sustainable, Global Warming, Adaptation, CMIP}

\section{Introduction}

Sugarcane industries worldwide make a valuable contribution to sustainable development. Sugarcane has been grown under many different climates to produce raw and refined sugars. Aside from cereal crops, sugarcane is the largest contributor of carbohydrates for human consumption [1]. The conversion of sugarcane to raw sugar produces a wide variety of important by-products such as bioenergy, biofuels, bioplastics, paper, animal feed and synthetic fertilizers [1]-[5]. Given the challenges of delivering sustainable solutions to employing, feeding and fuelling an increasing global population, it is timely and critical to understand that the impact climate change will have on sugarcane production, especially since sugarcane is one of the most efficient crops in terms of solar radiation capture, photosynthesis and energy production [4].

A number of climate change impact studies have been conducted for sugarcane production systems around the world. Most studies use the DSSAT-Canegro [6] or the APSIM [7] cropping systems simulators. Using DSSATCanegro [6], Knox et al. [8] reported 2050 biomass for Swaziland to increase by $15 \%$ under the elevated $\mathrm{CO}_{2}$ A2 emission scenario and only $5 \%$ without increases in $\mathrm{CO}_{2}$. The DSSAT-Canegro model has also been used by Marin et al., [9] with three harvest dates to project São Paulo stalk fresh matter yields for 2050. Marin et al. [9] derived climate scenarios (SRES A2 and B2) from two GCMs, PRECIS and CSIRO. $\mathrm{CO}_{2}$ concentrations were fixed at $380 \mathrm{ppm}, 500 \mathrm{ppm}$ and $720 \mathrm{ppm}$ for baseline, B2 and A2 simulations, respectively. Stalk fresh matter increased by $1 \%$ (late harvest, PRECIS, B2) to 54\% (early harvest, A2, PRECIS). Another study found yields to increase in Australia (Ayr), Brazil (Piracicaba) and South Africa (La Mercy) by 4\%, 9\% and 20\%, respectively when they used outputs from GCMs and an elevated $\mathrm{CO}_{2}$ concentration of $734 \mathrm{ppm}$ [10].

Several APSIM [7] driven impact studies have been conducted in Australia [11]-[13]. Park et al. [12] simulated Maryborough sugarcane yields for 2030 and 2070. Simulations considered three local soil types and two irrigation scenarios. The historic climate data were altered according to the wettest and driest climate change projections (with 25 different temperature and rainfall changes being used in their study), as simulated by 15 global and regional climate models for 2030 and 2070. An atmospheric $\mathrm{CO}_{2}$ concentration of $437 \mathrm{ppm}$ and 610 ppm was used for 2030 and 2070, respectively. For 2030 the best modelled outcome was an increase in yield of approximately $7 \%$ and the worst a decrease of around $4 \%$. By 2070 the largest increase was $7 \%$ but potential reductions of $47 \%$ were modelled.

Webster et al. [13] projected yields for the Tully-Murray catchment in the far northern wet tropical sugarcane growing regions of Australia. Future climates for 2030 and 2070 were considered with three rainfall and temperature scenarios that were obtained by multiplying a baseline climatology for Tully with projected extremes and averages of these extremes [14]. The same atmospheric $\mathrm{CO}_{2}$ concentrations as in Park et al. [12] were utilised (437 ppm and 610 ppm for 2030 and 2070, respectively). A soil type common in the Tully-Murray catchment was used for all simulations. Slight increases in sugarcane yield (maximum of $+5 \mathrm{t} / \mathrm{ha}$ ) for 2030, were projected for all rain-temperature scenarios. By 2070, only a low temperature increase in conjunction with average or high rainfall led to a projected yield improvement (up to $+7 \mathrm{t} / \mathrm{ha}$ ).

Biggs et al. [11] used APSIM to investigate the impact of different management systems on sugarcane yield and nitrogen loss via deep drainage or runoff, under current climates and the different climate change projections. They derived the future climate change projections from three GCMs, in which an atmospheric $\mathrm{CO}_{2}$ concentration of $437 \mathrm{ppm}$ for 2030 was assumed. The projected impacts of these models ranged from weak (modestly warmer and wetter), moderate (mid-range warmer and drier) to strong (significantly warmer and drier) climate change. To obtain these scenarios, SRES B1, A1B and A1FI were used, respectively. The GCM projections were obtained from OzClim at a resolution of about $25 \mathrm{~km}$ by $25 \mathrm{~km}$. Median sugarcane yields increased by $8 \%$ and $4 \%$ with weak and moderate climate change, respectively, but were reduced by $10 \%$ with strong climate change. They ran APSIM with and without the effects of rising $\mathrm{CO}_{2}$. Yields under elevated $\mathrm{CO}_{2}$ were $10 \%$ - 14\% larger than those produced with the identical climate scenario but without elevated $\mathrm{CO}_{2}$.

Santos et al. [15] did not use DSSAT-Canegro or APSIM, instead they used the Agro-Ecological Zone model 
(AZM) [16]. Their study reported Brazilian sugarcane yields would increase by 51\% in Jaboticabal to $82 \%$ in Aracatuba by 2090. They considered three concentrations of $\mathrm{CO}_{2}$ (440 ppm, 559 ppm and 721 ppm) and attributed these increases in sugarcane productivity to elevated $\mathrm{CO}_{2}$ and higher temperatures.

This brief overview of climate impacts on sugarcane yields reflects a range of modelling approaches that incorporate different climate scenarios, $\mathrm{CO}_{2}$ levels, cropping systems simulators, climate projections, statistical downscaling methods, locations and management strategies. Results have varied markedly from yields losses of $47 \%$ [12] to increases of $82 \%$ [15]. Although most studies report the favourable outcome of increased productivity with elevated $\mathrm{CO}_{2}$ levels (e.g. [8] [9] [13] [15]) there is a need to consider climate change impacts studies that simultaneously and robustly integrate across a broad range of cropping systems and climate projections.

Therefore, the objectives of this paper are to simulate yields generated from 11 GCM scenarios for three major sugarcane growing regions in Australia. Ensembles captured for both the agricultural and climate systems form part of the dual ensemble agroclimate modelling procedure. Ensembles have been considered favourably since they offer the ability to capitalise on the strengths of a collection of simpler models [17].

\section{Productivity and Climate Data}

\subsection{Productivity Data}

The total amount of cane harvested divided by the hectares harvested within a region produced regionally averaged sugarcane yields (t/ha) as,

$$
\text { yield }(\text { region, year }) \mathrm{t} / \mathrm{ha}=\frac{\text { tonnes of cane harvested }(\text { region, year })}{\text { total hectares harvested }(\text { region, year })}
$$

Using Equation (1), regional yields were computed each year from 1971 to 2000 from the Burdekin, Mackay and New South Wales (NSW). This period aligned with both observed climate data and climate data that were simulated on a grid [18]. Trends in yield productivity were negligible in the Burdekin $\left(r^{2}<0.01 ; p=0.99\right)$, but significant in Mackay $\left(r^{2}=0.11 ; p=0.04\right)$ and NSW $\left(r^{2}=0.34 ; p<0.01\right)$. To avoid confounding changes in production caused by time trends in Mackay and NSW, yields for these two regions were detrended using the "loess" function in R [19]. In 2000 yields from the Burdekin and Mackay were devastated by disease and omitted from the analyses.

\subsection{AWAP Climate Data Used to Model Historical Regional Yields}

Climate data from northern (the Burdekin), central (Mackay) and southern (New South Wales (NSW)) Australian sugarcane-growing regions were utilised in this study. Daily rainfall and temperatures (maximum and minimum) for the years 1970 to 2000 were extracted from the Australian Water Availability Project (AWAP) data set [18], which interpolates data on a $0.05^{\circ} \times 0.05^{\circ}$ "pixel” grid. Pixels that represented locations (latitude and longitude) where sugarcane was known to be grown were identified. Only climate data for these pixels were used in the regional analyses. These rainfall and temperature data were used to estimate radiation [20]. There were 64, 133 and 77 pixels for the Burdekin, Mackay and New South Wales, respectively (Figure 1).

\subsection{GCM Generated Climate Data}

General circulation models (GCMs) from the Coupled Model Intercomparison Project (CMIP3) [21] that produced daily records of rainfall and temperature were used in subsequent analyses (Table 1). These GCMs were parameterized according to three different emission scenarios referred herein as “20C3M", "B1" and “A2”. Under the 20C3M scenario, the GCMs applied 20"th century emissions [22]. Outputs for this scenario spanned 1970 to 2000. The B1 scenario, which has a lower population growth rate and a more rapid technological change than the A2 scenario, parameterizes the 11 GCMs to represent a low emissions future [23]. The A2 scenario represents a higher emission future [23] but is still slightly below the actual observed emissions trajectory to date. Outputs for the B1 and A2 scenarios covered 2046 to 2065.

Statistical downscaling was necessitated as Australia's sugarcane industry, situated between high mountain ranges and the narrow eastern coast, operates under a highly variable geographical domain. The statistical downscaling method of [24] was employed as it was found for Australia to be largely unbiased and reproduced the main characteristics of the probability density functions of local observed variables. It is simple, flexible and 


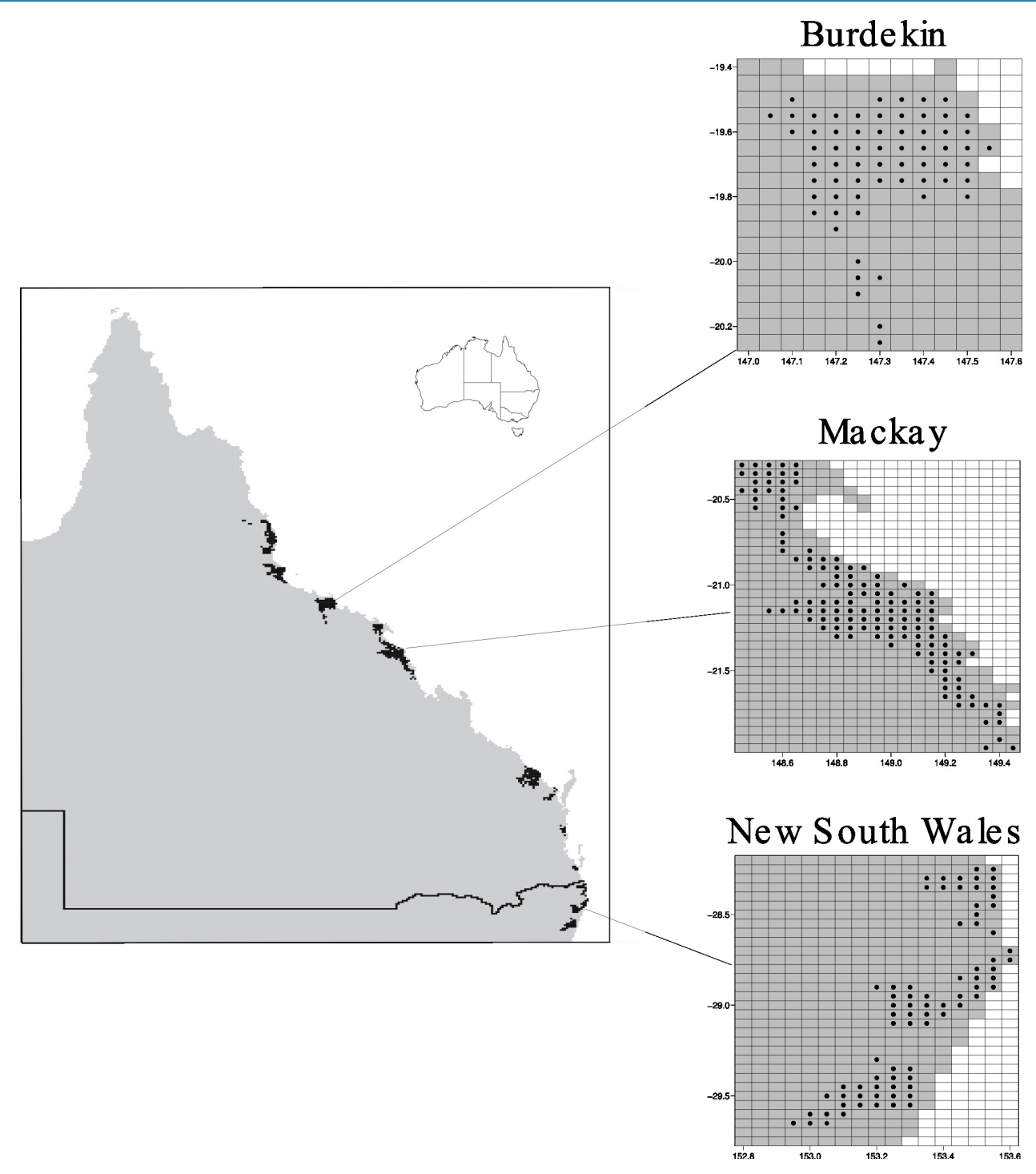

Figure 1. Sugarcane growing regions along the east Australian coast (black), with regions considered in this study highlighted.

Table 1. Eleven general circulation models with daily rainfall data.

\begin{tabular}{ccl}
\hline ID Number & ID Code & Institute \\
\hline GCM1 & CCM & Canadian Climate Centre \\
GCM2 & CNRM & Metro-France \\
GCM3 & CSIRO & Commonwealth Scientific and Industrial Research Organisation \\
GCM4 & CSIRO2 & Commonwealth Scientific and Industrial Research Organisation \\
GCM5 & GFDL1 & Geophysical Fluid Dynamic Lab \\
GCM6 & GFDL2 & Geophysical Fluid Dynamic Lab \\
GCM7 & GISSR & NASA/Goddard Institute for Space Studies \\
GCM8 & IPSL & Institute Pierre Simon Laplace \\
GCM9 & MIROC & Centre for Climate Research \\
GCM10 & MPI & Max Planck Institute for Meteorology DKRZ \\
GCM11 & MRI & Meteorological Research Institute
\end{tabular}


robust which are important elements for communicating findings to industry. Timbal et al. [25] developed a series of mathematical equations that related the observed daily synoptic patterns to observed daily rainfall, maximum and minimum temperature. These mathematical equations were subsequently applied to the synoptic patterns generated by the 11 GCMs for the 20C3M, B1 and A2 scenarios. This downscaling approach has been applied with success in several impacts studies [26]-[28]. Daily radiation was estimated from the statistically downscaled rainfall and temperature using the method of Liu and Scott [20].

\subsection{GCM Generated Climate Data}

$\mathrm{CO}_{2}$ levels were computed for the historic period 1970-2000 (345 ppm) and the 2046-2065 period for the B1 (493 ppm) and A2 (548 ppm) scenarios. These values were obtained by averaging the annual linearly interpolated $\mathrm{CO}_{2}$ values [29] for the time periods in our study. Decadal $\mathrm{CO}_{2}$ concentrations in ppm were extracted from http://www.ipcc-data.org/ancilliary/tar-bern.txt for each scenario. Our values are in close agreement with Tebaldi and Lobell [30] and Semenov and Stratonovitch [31].

\section{Modelling Sugarcane Yields}

Yields were simulated using a combination of previously published algorithms from Canegro and WaterSense sugarcane growth models (Section 3.1) modified to incorporate $\mathrm{CO}_{2}$ effects (Section 3.2). A realistic set of management and environmental interactions that represented the regional production conditions were simulated using this crop (Section 3.3). An ensemble of crop model outputs that best accounted for historic yields in each region was obtained (Section 3.4). The best ensemble for each region was then used with the crop model and with downscaled GCM outputs under the 20C3M, B1 and A2 scenarios, to simulate changes in sugarcane yields from the present climate to the climate projected for the mid $21^{\text {st }}$ century (Section 3.6). Uncertainty in the climate ensemble was assessed using bootstrapped confidence intervals (Section 3.7).

\subsection{The Crop Model}

A model for simulating historical yields is needed so that yields can be estimated from projected climates. For this study we used WaterSense logic [32] but we replaced the crop coefficient approach with one in which evapotranspiration estimates vary with crop height and leaf area index as reported by [33]. In this procedure latent heat flux is derived from the Penman-Monteith (PM) equation (Equation (2)) and functions for wind speed, canopy and aerodynamic resistance. This was done to allow estimates of leaf conductance to be scaled up to an estimate of canopy conductance of a field crop. WaterSense is a web-based irrigation scheduling system developed from concepts embodied in the two internationally available models for sugarcane, APSIM-Sugarcane and Canegro [34].

Development of the leaf canopy and radiation interception and biomass accumulation in the crop model for this paper were based on APSIM-Sugarcane [7] and the water balance is essentially the same as in Canegro [35] before incorporation into the DSSAT platform. Leaves emerge as defined by the user in terms of thermal time. Final area of successive leaves is also defined by the user as are the number of stalks per square meter and the contribution of tillers to total leaf area. Beers law is used to calculate the proportion of radiation captured by leaves using an extinction coefficient of 0.38 for solar radiation (a higher coefficient is warranted for photosynthetically active radiation). Potential transpiration is obtained from the PM formula as described by Inman-Bamber and McGlinchey [33] and Inman-Bamber et al. [35] and evaporation from the soil surface is obtained from the amount of radiation reaching the soil surface and the water content of the top layer of soil [32]. The soil is divided into as many as 20 layers to determine gravitational and capillary vertical flux of water [36] and root water extraction is performed as in APSIM-Sugarcane using water extraction coefficients $k_{L}$, [7] rather than the more complex root length development approach used in Canegro [37].

\subsection{Incorporating $\mathrm{CO}_{2}$ Effects into the Water Sense Crop Model}

Stomatal resistance to gaseous diffusion $\left(r_{\mathrm{s}}\right)$ was set to increase approximately $12 \%$ per $100 \mathrm{ppm}$ increase in $\mathrm{CO}_{2}$ concentration and potential transpiration $\left(T_{0}\right)$ was computed using the PM formula (Equation (2))

$$
T_{0}=\frac{\Delta\left(R_{n}-G\right)+\rho c_{p} V P D_{2} / r_{a}}{\left(\Delta+\gamma\left(1+r_{c} / r_{a}\right)\right) \lambda}
$$


where

$c_{p}=$ specific heat of air at constant pressure $(\mathrm{J} / \mathrm{kg} / \mathrm{K})$

$\Delta=$ slope of the vapour pressure curve $\left(\mathrm{kPa} /{ }^{\circ} \mathrm{C}\right)$

$G=$ soil heat flux density $\left(\mathrm{MJ} / \mathrm{m}^{2} /\right.$ day $)$

$\gamma=$ psychrometric constant $\left(\mathrm{kPa} /{ }^{\circ} \mathrm{C}\right)$

$\lambda=$ latent heat of vaporization of water $(\mathrm{J} / \mathrm{kg})$

$R_{n}=$ net radiation $\left(\mathrm{MJ} / \mathrm{m}^{2} / \mathrm{d}\right)$

$\rho=$ air pressure $(\mathrm{kPa})$

$r_{a}=$ aerodynamic resistance $(\mathrm{s} / \mathrm{m})$

$r_{c}=$ canopy surface resistance $(\mathrm{s} / \mathrm{m})=r_{s} /(0.5 \times$ Leaf Area Index $)$

$r_{\mathrm{s}}=$ stomatal resistance $(\mathrm{s} / \mathrm{m})$.

The year 1965, when $\mathrm{CO}_{2}$ concentration was approximately $325 \mathrm{ppm}$, was regarded as a benchmark for setting $r_{\mathrm{s}}=100 \mathrm{~s} / \mathrm{m}$ because this is when detailed lysimeter work was conducted to validate the PM procedure for determining evapotranspiration from sugarcane [33]. The period 1960 to 2000 represented the 'present' period and a $\mathrm{CO}_{2}$ concentration of $345 \mathrm{ppm}\left(r_{\mathrm{s}}=102 \mathrm{~s} / \mathrm{m}\right)$ was assumed for this period. Daily climate data records obtained from the AWAP (Section 2.2) estimated observed climate data for this period. Representative climate data for this period were also obtained for 11 downscaled GCM simulations, based on the 20C3M scenario (Section 2.3). For the future period 2046 to 2065, $\mathrm{CO}_{2}$ concentrations were assumed to be $493 \mathrm{ppm}\left(r_{s}=121 \mathrm{~s} / \mathrm{m}\right)$ for simulations under the B1 scenario and $548 \mathrm{ppm}$ under the A2 scenario $\left(r_{s}=128 \mathrm{~s} / \mathrm{m}\right)$.

\subsection{Defining Management and Environment Interactions}

Within each region sugarcane is grown under a wide variety of management and environmental interactions. Harvesting in each region operates continuously from July to October each year and three harvest start dates, mid-June, mid-August and mid-October were chosen to represent all crops. Lodging was simulated based on crop yield and storm severity following rules developed by [38]. We allowed lodging to have no effect on photosynthesis (L0), or to reduce photosynthesis by 30\% (L1) or by 50\% (L2). Two maintenance respiration levels were considered-no respiration (R0), and respiration of $0.4 \%$ of total dry mass per day (R1) in line with the daily maintenance respiration used in the Canegro model [39].

Irrigation strategies differ for each region. The Burdekin is a fully irrigated production system. Here growers tend to irrigate on a calendar basis rather than using any information about the soil water balance. Irrigation is usually applied during germination or regeneration after harvesting and then at 3 or 4 weekly intervals until the canopy is well developed. After that, irrigation may be applied at 7 to 14 day intervals unless rain has filled the profile. This variety of practices was captured in the simulations by allowing deficits of 20, 40, 60 or $80 \mathrm{~mm}$ to develop before irrigating with $100 \mathrm{~mm}$, provided 7 days had lapsed since the last irrigation. Irrigation is applied on a supplementary basis in the Mackay region normally in the range of 100 to $500 \mathrm{~mm}$ total, during periods when rainfall is low. The model applied $50 \mathrm{~mm}$ of irrigation when the deficit reached $40 \mathrm{~mm}$ provided 14 days had lapsed since the last irrigation thus acknowledging that most growers in this region do not have the infrastructure required to irrigate more frequently. Irrigation is not usually applied in the NSW region because of the high rainfall and presence of shallow water tables. Growers do not plant when soils are dry and so an irrigation of $50 \mathrm{~mm}$ was allowed in the simulation to ensure that germination could occur. Another option for a total of $200 \mathrm{~mm}$ irrigation was allowed, to cater for situations where additional water would be available to the crop from water tables that may be accessed by the crop during dry periods [40].

The main difference between soils pertinent for this study is in their plant available water capacity (PAWC). Data for in-situ rooting depth and PAWC is available for a limited number of soils in the sugar industry. We used the PAWC values obtained from water retention studies in the laboratory combined with neutron soil moisture measurements and stalk elongation measurements [41] to represent poor (PAWC = 88 mm), moderate $(\mathrm{PAWC}=180 \mathrm{~mm})$ and $\operatorname{good}(\mathrm{PAWC}=267 \mathrm{~mm})$ soils in regard to their water storage properties. These PAWCs are comparable to those measured or used in previous simulation studies representing the Mackay and Burdekin regions [11] [42]-[45]. Unfortunately soils in NSW have not been characterized for use in models such as APSIM, Canegro or WaterSense as far as we know but the soils in that region are likely to vary from poor to good as in all other regions.

The same generic crop parameters were used for all three regions. While this parameter set was used to rep- 
resent elite sugarcane varieties in general, it most closely resembles the variety Q117 because canopy development traits have been characterised the best for this variety [7]. There is insufficient data to characterise individual varieties in the detail required for simulating their yield physiology [46].

The cropping cycle in sugarcane can be quite complex because the crop can be fallowed and planted at any time of year and it can be harvested between June and November (approximately) in Australia. Climate change may influence the interaction between these factors and crop yield. As far we know there is no information on these interactions for future climates and we expect that these effects will be small compared to the more direct effects of rainfall, temperature, radiation and $\mathrm{CO}_{2}$ change on yield. We avoided complex interactions between climate, crop planting and harvest dates by "ratooning" a crop each year on a given day. Thus the model simulated 30 years of successive ratoon crops with no fallow period and while this is not normal practice it fits with the aim of the study to compare current yields with future yields in a changed climate.

In total there were 216 crop model parameterisations for the Burdekin, 162 for Mackay and 108 parameterisations for New South Wales (Table 2). The crop model required climate inputs of daily rainfall, maximum temperature and minimum temperature. Spatially averaging climate data within a region was considered inappropriate owing to the geographical diversity of the regions, so daily atmospheric data were derived for each pixel (Figure 1) of the study regions (Sections 2.2 and 2.3).

\subsection{Ensemble Averaging}

Most agroclimate modelling procedures derive ensembles from climate models but not from crop models [47]. To better capture uncertainties in the crop growing environment it has been recommended to use multiple sets of crop model parameterisations which we refer to as "members" [48]-[52]. Combining several members instead of using the "best" individual member as part of an ensemble modelling process produces a more stable and often more accurate model than any individual member [53] [54]. However, it can be advantageous to select a smaller number of members rather than working with all available members [55]. The forward stage-wise algorithm [55], was used for its computational efficiency to select a subset of members. The ensemble members were equally weighted for the purpose of stability and simplicity [53] [54]. The ensemble process was fully cross-validated using a leave one out approach to compute a predictive correlation. Further, Monte Carlo permutation testing was employed to calculate the significance of the predictive correlation and thus, that the ensemble members selected were unlikely a consequence of chance [48]. Our ensemble modelling process follows Everingham et al. [48].

Table 2. Factor and level combiations (treatments) which defined the different crop model parameterisations.

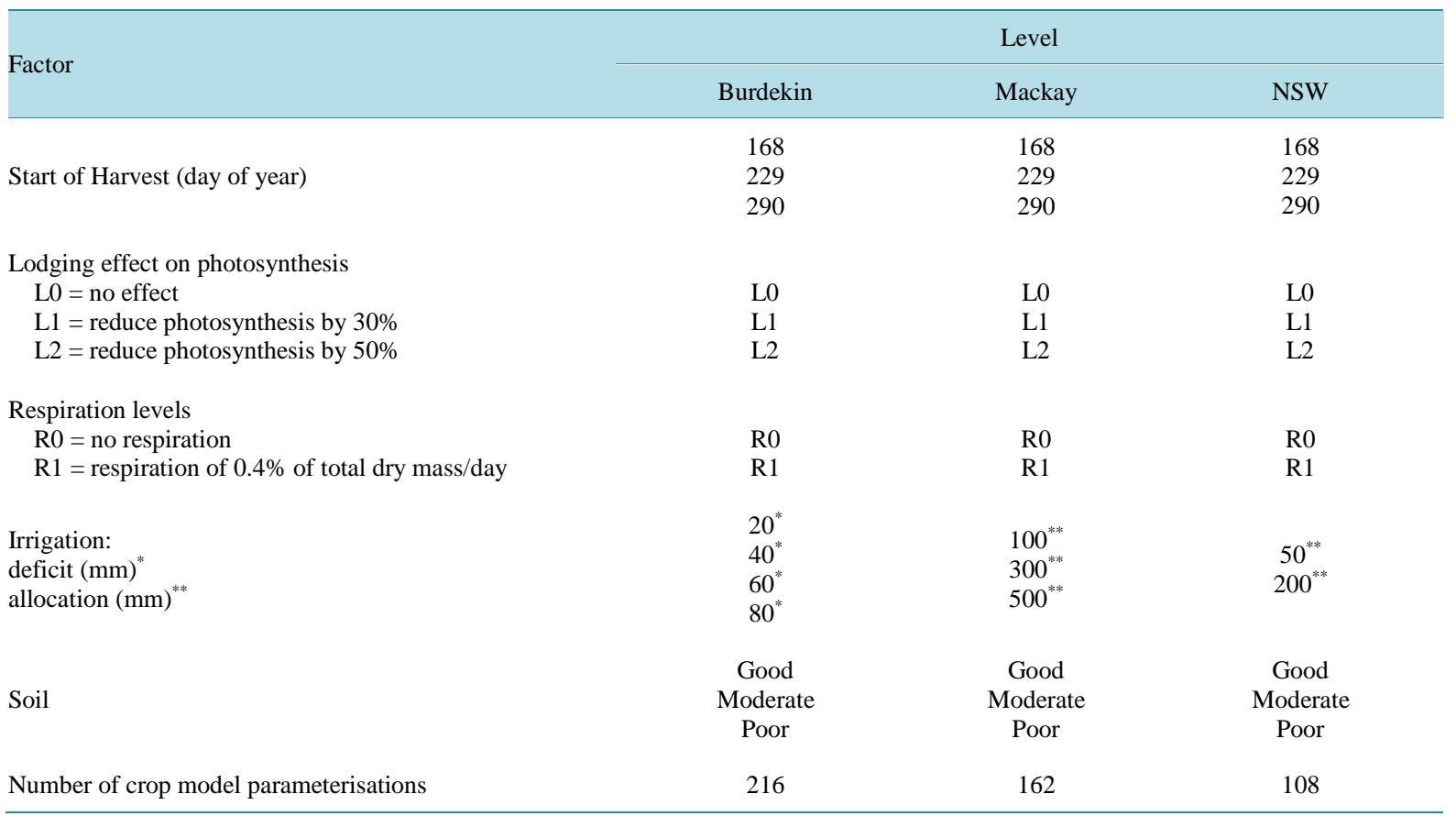




\subsection{Crop Model Validation}

\subsubsection{AWAP Modelled Yields versus Observed Yields}

The leave one out cross-validated predictive correlation (see Section 3.4) was used to measure the strength of the association between the actual yields and the yields generated from the AWAP climate data. Cumulative distribution functions (CDFs) of these two sets of yields were inspected visually to check for biases. The cumulative distribution function was used to describe the probability ('density') that yields were less than or equal to a certain value. Different sets of yield data, which have similar shaped CDFs, will have similar yield distributions. These checks were performed to gauge the suitability of the model selection procedure, and hence if the crop ensemble model could be applied to the GCM-generated climate data produced with 20C3M, B1 and A2 forcings.

\subsubsection{AWAP versus 20C3M Modelled Yields}

Given that sugarcane is a perennial crop and GCM generated data cannot be compared temporally, it is important to check the alignment of yield distributions generated from the AWAP climate data and from GCM generated data under the 20C3M scenario. Or, if a discrepancy exists it should be consistent so that the relative change in yields within each of the GCM models is meaningful. Cumulative distribution functions of yields for each GCM were compared visually to that of AWAP generated yields.

\subsection{Comparing Future and Historic Generated Yields from GCM-Generated Climate Data}

Future regional yields were generated by substituting the GCM generated yields into the final model developed from the AWAP climate data on observed climate yields (Section 3.4.1). The change in the models' yield projections were computed for the B1 and A2 scenarios, relative to the baseline 20C3M scenario. We explain the methodology for the B1 scenario. The methodology for the A2 scenario follows similarly. The relative percentage change of the paired differences in mean yields $\bar{Y}$ (region, GCM, scenario) for each downscaled GCM were calculated as,

$$
\left.\begin{array}{c}
\frac{\bar{Y}(\text { region, GCM1, B1 })-\bar{Y}(\text { region, GCM1, 20C3M })}{\bar{Y}(\text { region, GCM1, 20C3M })} \times 100 \% \\
\frac{\bar{Y}(\text { region, GCM2, B1 })-\bar{Y}(\text { region, GCM2, 20C3M })}{\bar{Y}(\text { region, GCM2, 20C3M })} \times 100 \% \\
\vdots \\
\frac{\bar{Y}(\text { region, GCM11, B1 })-\bar{Y}(\text { region, GCM11, 20C3M })}{\bar{Y}(\text { region, GCM11, 20C3M })} \times 100 \%
\end{array}\right\}
$$

A boxplot of the values in Equation (3) for B1 and the equivalent for A2 was produced so that the central distribution of the differences defined by the $25^{\text {th }}, 50^{\text {th }}$ and $75^{\text {th }}$ percentile could be readily detected. Superimposed on the boxplot are the individual model projections. Downscaled GCMs that produce large positive values in Equation (3) indicate a relative increase (positive change) in yields under B1 forcings compared to $20^{\text {th }}$ century forcings (20C3M). Downscaled GCMs that produce large negative values indicate a relative decrease (negative change). Values close to zero indicate a neutral change.

\subsection{Assessing the Uncertainty in the Climate Ensemble Using Confidence Intervals}

Equation (3) represents a sample of 11 yields simulated by the 11 downscaled GCMs. We assume this sample to be independent and representative of a larger parent population. The eleven models considered form a reasonable spread across the families of GCMs identified by [56] for rainfall and temperature which derived our yield estimates and so we consider this a reasonable assumption for the purpose of generating confidence, especially when "there is no guarantee that the level of interdependence will be the same for all variables, for all seasons, or for all locations" and "estimates of interdependence based on contrasts in simulations of the climatology very likely overestimate interdependence among projections" [57].

To identify how the central distribution of yields shifts with climate change, separate $95 \%$ confidence intervals for the $25^{\text {th }}, 50^{\text {th }}$ and $75^{\text {th }}$ population percentiles of differenced yield projections were computed using boot- 
strapped samples [58]-[60]. We consider increasing yields to be 'plausible' when the confidence intervals for the $50^{\text {th }}$ and hence the $75^{\text {th }}$ percentile were greater than zero, and 'highly plausible' if the confidence intervals for the $25^{\text {th }}$ and hence the $50^{\text {th }}$ and $75^{\text {th }}$ percentiles were all greater than zero [58] [61]. By extension, we consider decreasing yields to be "plausible" when the confidence intervals for the $50^{\text {th }}$ and hence the $25^{\text {th }}$ percentiles were less than zero, and "highly plausible" if the confidence intervals for the $75^{\text {th }}$ and hence the $50^{\text {th }}$ and $25^{\text {th }}$ percentiles were all less than zero.

\section{Results}

The majority of ensemble members used the poor soil (PAWC $=88 \mathrm{~mm}$ ) for both the Burdekin and Mackay regions while ensemble members for the NSW region largely used the moderate soil (PAWC = $180 \mathrm{~mm}$ ). Crop ensemble members in the Burdekin region used 20, 40, 60 and $80 \mathrm{~mm}$, the Mackay region favoured an irrigation of $100 \mathrm{~mm}$ and the NSW region used both $50 \mathrm{~mm}$ and $200 \mathrm{~mm}$. Ensemble members for the Mackay and Burdekin regions preferred a late (day 290) harvest start date, while models in the NSW region used a mix of harvest start dates (days 168, 229 and 290). The Burdekin ensemble members heavily favoured the combination of moderate respiration of sucrose (R1) with no to low lodging (L0 and L1). The Mackay ensemble models favoured respiration of sucrose (R1), but had no preference for lodging. The NSW ensemble models had no preferential respiration and higher lodging (L2) was prevalent in the ensemble members. Ensemble members in each regional ensemble used climate data from across the region. However, the far west of the Burdekin region was largely excluded (Figure 2). The north of the Mackay region and the western central Section of the NSW region were also excluded. Across these pixels within each of these regions the mean annual temperatures increased, radiation decreased and rainfall was quite variable (Figure 3 ).

Cumulative distribution functions (CDFs; see Section 3.5.1) between ensemble predictions generated from the AWAP data and observed yields are shown in Figure 4. For example, in the Mackay region (Figure 4(b)) there is a $60 \%$ chance of obtaining both an observed and modelled yield less than 80 t/ha. Most CDFs showed medium to strong correspondences (Figure 4). This was confirmed by the significant predictive correlations generated from the permutation tests (see Section 3.4) for the Burdekin, Mackay and NSW: $0.69(p=0.030), 0.83(p$ $<0.001)$ and $0.70(p=0.034)$, respectively. Thus, the crop ensemble model which utilised the AWAP data was deemed appropriate for assessing climate change impacts on yields. The CDFs of yields in Figure 5 produced by the downscaled GCMs closely followed the CDF of the AWAP generated yields for the Burdekin, but tended to underestimate yields for Mackay and overestimate yields New South Wales. If we assume these biases remain consistent into the future, then relative changes in yields may still be investigated.

Figure 7 shows boxplots of the projected relative changes in yields for each of the downscaled GCMs with and without the effect of elevated $\mathrm{CO}_{2}$. Elevated $\mathrm{CO}_{2}$ levels for both the $\mathrm{B} 1$ and $\mathrm{A} 2$ scenarios produced the greatest yield benefits in NSW followed by Mackay (Table 3). The Burdekin region received the smallest benefit from elevated $\mathrm{CO}_{2}$ levels.

When increased $\mathrm{CO}_{2}$ levels were considered, confidence intervals of the $25^{\text {th }}, 50^{\text {th }}$ and $75^{\text {th }}$ percentiles (Figure 8(a)) indicated an increase in yield performance was "plausible" for all three regions under the low emission scenario and "highly plausible" for the NSW region under the high emissions scenario (see Section 3.7). If the effect of increased $\mathrm{CO}_{2}$ was ignored (Figure 8(b)) there was insufficient evidence to support a change in yields for any region. The confidence interval spread was largest for New South Wales, followed by Mackay and the Burdekin.

\section{Discussion}

In the irrigated Burdekin region, rising $\mathrm{CO}_{2}$ is projected to have little effect on yields (Figure 8), but would slightly reduce the amount of irrigation required (Figure 6 and Figure 7). In a study on the impact of water stress in the Australian sugar industry, water deficits were found to reduce yields in the Burdekin by only $4.4 \%$ [62] and, provided irrigation supplies remain unlimited in this region, elevated $\mathrm{CO}_{2}$ can help increase yield only by reducing this small impact of water stress hence the small positive effect of increased $\mathrm{CO}_{2}$ on projected yields with climate change (Figure 8). Projections of Burdekin yields under the B1 scenario were marginally higher than yields for the A2 scenario, which was consistent with the greater decline in radiation for the A2 scenario (Figure 3). A higher temperature in a future climate was likely responsible for the projected plausible increased yield in the Burdekin for the B1 scenario (Figure 3). While this temperature increase is projected to be 

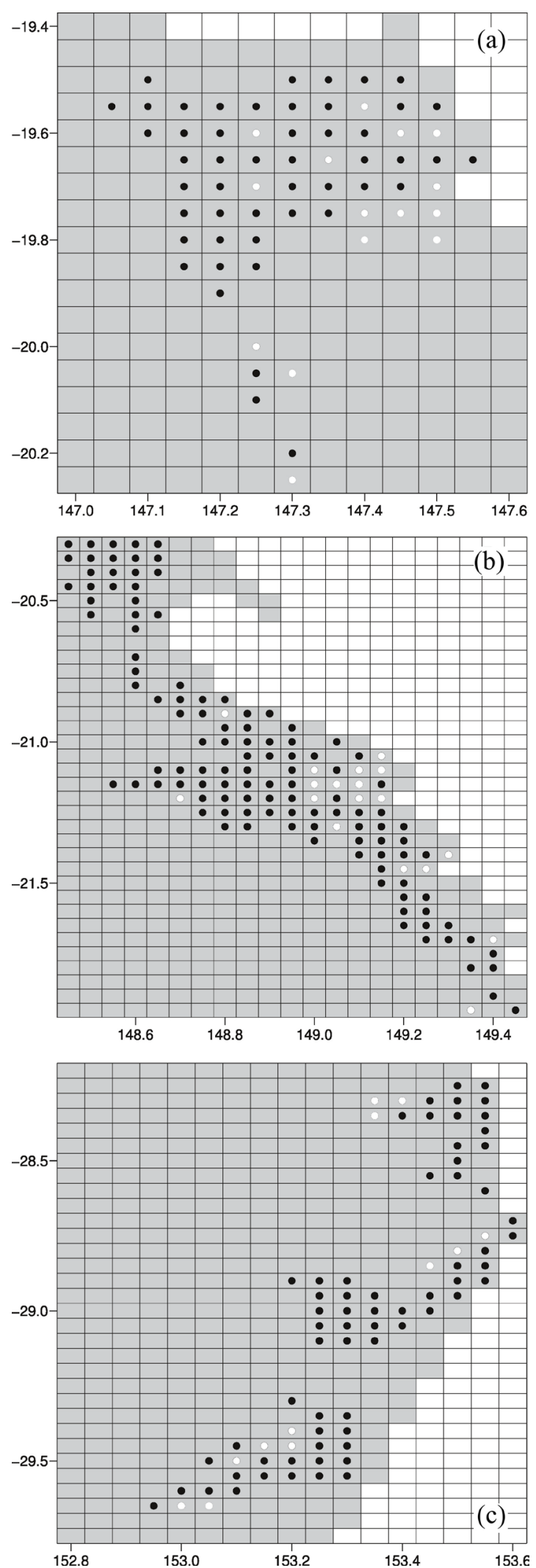

Figure 2. Climate data pixels (white points) selected in crop ensemble members for (a) Burdekin, (b) Mackay and (c) New South Wales. 

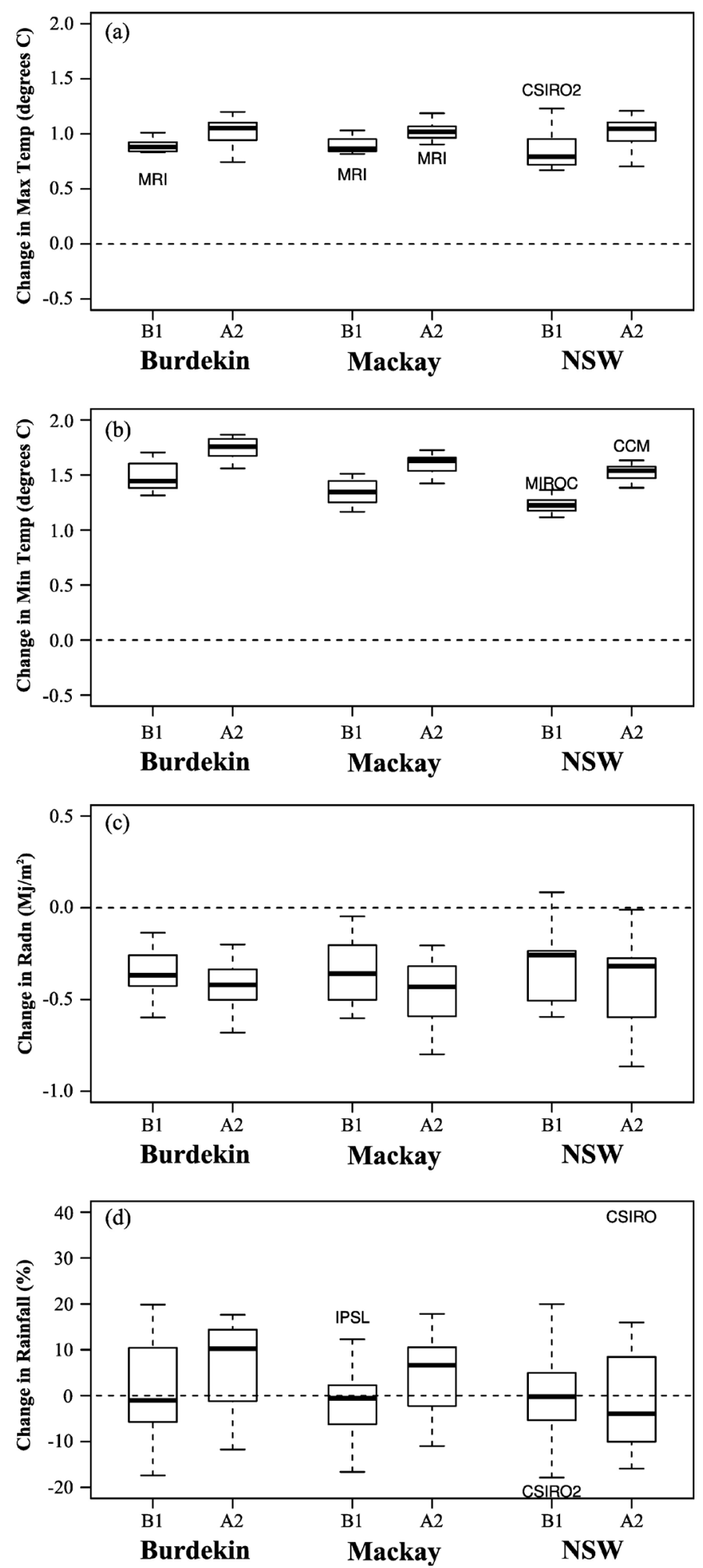

Figure 3. Change in annual mean (a) maximum temperature, (b) minimum temperature, (c) radiation and (d) rainfall for the selected climate data pixels used in ensemble members for the Burdekin, Mackay and New South Wales. The mean was computed by averaging across time and across the white climate data pixels selected in the ensemble (see Figure 2). Boxes mark the first, second (median) and third quartile and the "whiskers" mark the maximum and minimum excluding outliers. Outlier GCMs are labelled. 

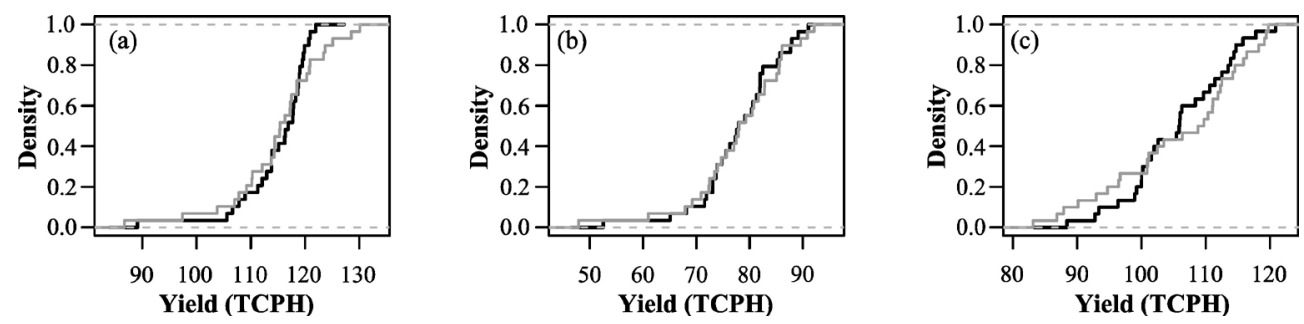

Figure 4. Cumulative distribution functions of observed (grey line) and modelled yields (black line) for 1971 to 2000 for (a) Burdekin, (b) Mackay and (c) New South Wales. Modelled yields were generated from AWAP inputs.
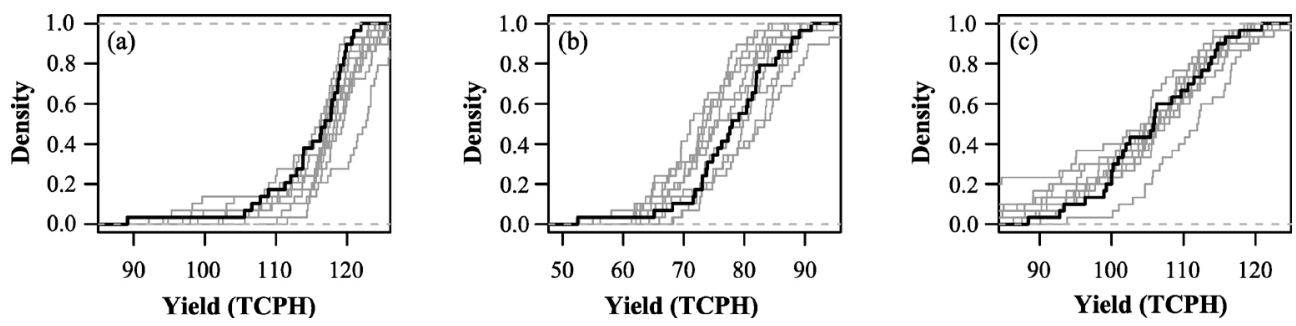

Figure 5. Cumulative distribution functions of annual yields across 1971 to 2000 for (a) Burdekin, (b) Mackay and (c) New South Wales. Yields were estimated from AWAP inputs (black line) and downscaled GCM simulated yields with 20C3M forcings.
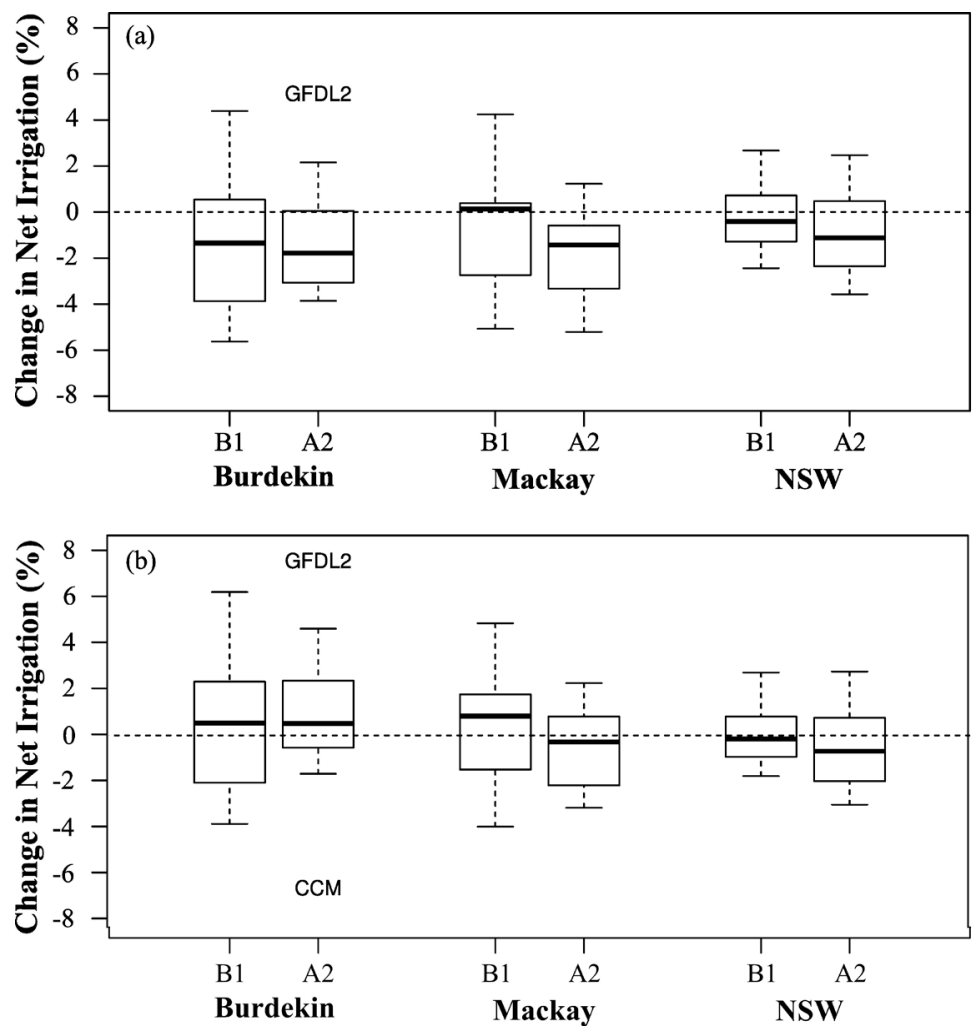

Figure 6. Change in annual mean net irrigation (a) with a $\mathrm{CO}_{2}$ effect and (b) without a $\mathrm{CO}_{2}$ effect.

higher for the A2 than the B1 scenario, reduced radiation detracted from the yield increase due to temperature particularly for the A2 scenario. Also, additional rainfall with the A2 scenario can only help alleviate water stress which is not much of a consideration in the Burdekin (Figure 3(d)). Changes in the annual patterns of 

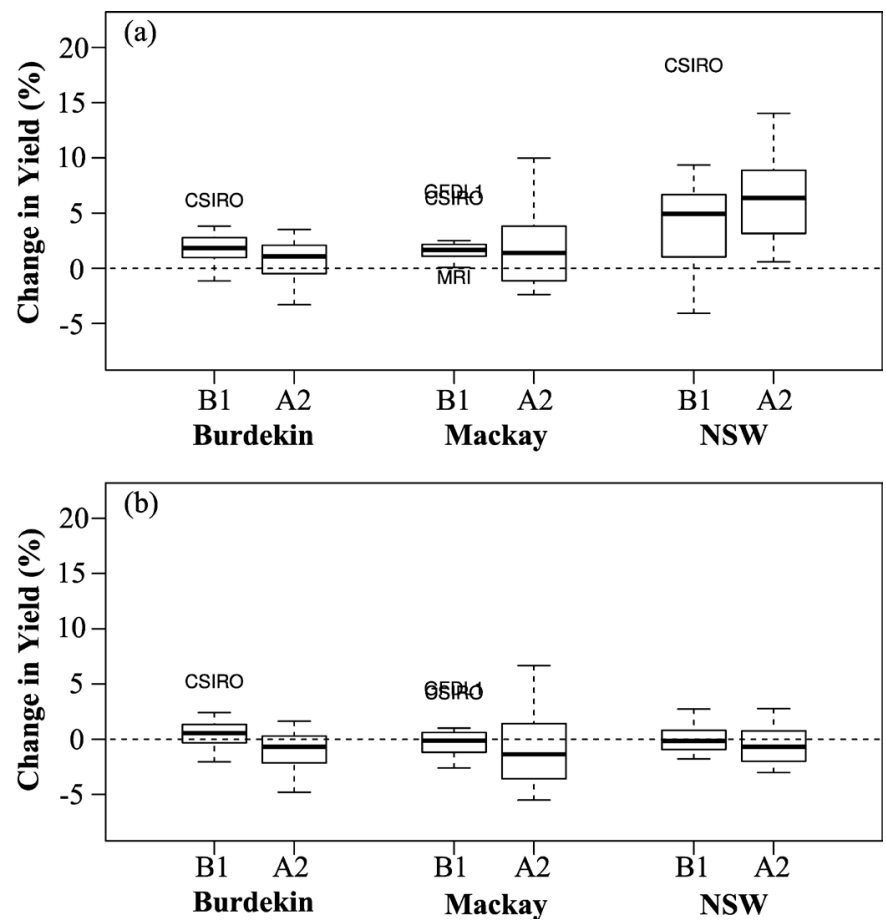

Figure 7. Boxplots of simulated yields under 20C3M forcings (a) with and (b) without increased $\mathrm{CO}_{2}$ levels. Boxes mark the first, second (median) and third quartile and the "whiskers" mark the maximum and minimum excluding outliers. Outlier GCMs are labelled.
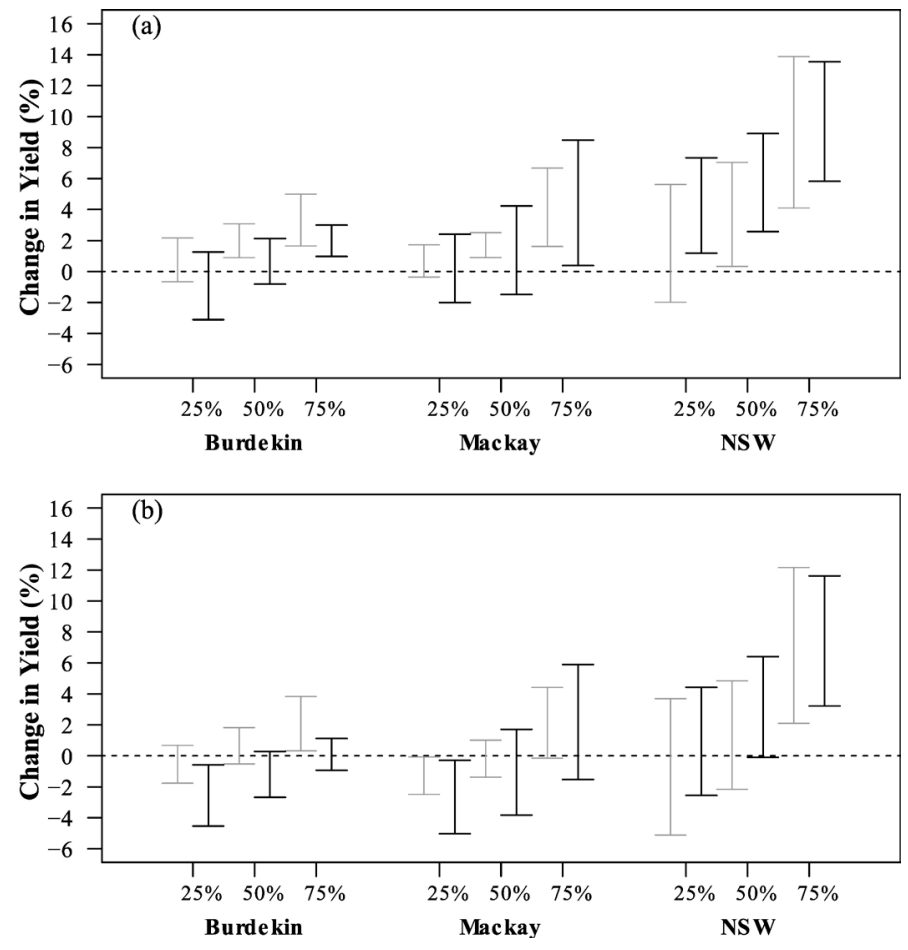

Figure 8. Boxplots of simulated yields under 20C3M forcings (a) with and (b) without increased $\mathrm{CO}_{2}$ levels. Boxes mark the first, second (median) and third quartile and the "whiskers" mark the maximum and mini- mum excluding outliers. Outlier GCMs are labelled. 
Table 3. Range of projected mean yield changes for B1 and A2 emissions scenarios with and without increased $\mathrm{CO}_{2}$ levels.

\begin{tabular}{cccc}
\hline \multirow{2}{*}{ Region } & $\mathrm{CO}_{2}$ effect & \multicolumn{2}{c}{ Climate Change Scenario } \\
\cline { 3 - 4 } Burdekin & With & -1.15 to 6.19 & -3.30 to 3.51 \\
& Without & -2.05 to 5.26 & -4.79 to 1.63 \\
Mackay & With & -0.79 to 6.38 & -2.39 to 9.98 \\
& Without & -2.60 to 4.60 & -5.51 to 6.67 \\
NSW & With & -4.07 to 18.40 & 0.58 to 14.03 \\
& Without & -7.37 to 17.03 & -3.09 to 12.11 \\
\hline
\end{tabular}

temperature and radiation are thus important and were captured adequately by the model.

The impact of the future climates on yield with a $\mathrm{CO}_{2}$ effect was potentially greater for Mackay and NSW regions than for the Burdekin region (Figure 7 and Figure 8). The loss in yield due to lack of water can be defined by a daily water stress index ( 0 to 1 ) where 1 is no water stress and 0 is no growth (highly stressed). The mean weighted water stress index for Mackay was 0.81 [62] thus total alleviation of water stress could lead to a substantial increase in mean yield from the region. Elevated $\mathrm{CO}_{2}$ will almost certainly help to alleviate some of this stress by allowing crops to assimilate $\mathrm{CO}_{2}$ while losing less water through transpiration. Thus, there was a plausible yield increase projected for Mackay for the B1 scenario when elevated $\mathrm{CO}_{2}$ was simulated but not so when the $\mathrm{CO}_{2}$ effect was disabled (Figure 3). The stress index for NSW was not determined by Inman-Bamber [62].

While the rise in temperature was projected to be similar in all regions, the impact of this rise would be greater in NSW than in other regions because NSW currently experiences temperatures well below critical temperatures at times for various growth processes and also experiences frost occasionally. Mean minimum temperature for July in NSW (Grafton) is $6.5^{\circ} \mathrm{C}$ compared to $11.6^{\circ} \mathrm{C}$ for the Burdekin (Ayr). Leaf extension ceases at about $10^{\circ} \mathrm{C}$ and photosynthesis at about $5^{\circ} \mathrm{C}$ [7] thus a $1^{\circ} \mathrm{C}$ increase in temperature is likely to be more effective in increasing yield in NSW than in the other regions further to the north.

Rainfall in the Australian sugar industry was thought to become more variable in future climates and atmospheric demand for water was expected to increase thus increasing the need for irrigation where this was available [63]. When rainfall was averaged across the pixels selected in the crop ensemble (Figure 2) we found projected increases in mean annual rainfall were just as likely as projected decreases in mean annual rainfall for the B1 scenario in all three regions, but increases were more likely for the Burdekin and Mackay for the A2 scenario (Figure 3). In all regions we allowed the crop to extract various amounts of water from irrigation or ground water if the demand increased. The maximum amounts increased from NSW (200 mm) and Mackay (500 mm) to an unlimited amount in the Burdekin. In the Burdekin, our simulations showed less irrigation would be necessary in a future climate (2046 to 2065) because of reduced transpiration in a $\mathrm{CO}_{2}$ enriched atmosphere (Figure 6). Changes in irrigation requirement given the current supply and infra-structure limitations for Mackay and NSW were inconclusive (Figure 6). Demands for irrigation water supply and infrastructure could decrease or increase by the same amount for Mackay and NSW without the effects of $\mathrm{CO}_{2}$, but when the effects of $\mathrm{CO}_{2}$ are considered, the pressures for irrigation water could decline in Mackay and NSW. Park et al. [63] listed a number of options for dealing with increased demand for water including increased irrigation efficiency and construction of more water storages.

The future climate scenarios we considered tended to have positive or neutral rather than negative impacts on sugarcane production. This is in contrast to many other crops and regions in Australia, where climate change impacts are more likely to be negative (e.g. [64]). Hence, climate adaptation is not just about coping with negative impacts, but also taking advantage of potential opportunities. For example, our studies indicate the benefits of increased transpiration efficiency (TE) mediated by increased $\mathrm{CO}_{2}$ concentration. An increase in TE due to genetic improvement will of course have the same benefits even at current $\mathrm{CO}_{2}$ levels provided the improved TE trait is not genetically correlated with detrimental traits. The search for variation in TE within the Australian 
gene pool has begun by [65] who suggest that such variation is indeed substantial. It is also possible that the response of stomata (hence TE) to rising $\mathrm{CO}_{2}$ could also vary in the local or worldwide gene pool. It would be well worth looking for such variation to introgress not only high TE traits but also high response to elevated $\mathrm{CO}_{2}$ into the germplasm. Successful introgression of such traits would benefit sugarcane industries worldwide particularly in future climates.

\section{Conclusions}

Sugarcane is the fastest growing, largest biomass and highest sucrose accumulating agricultural crop today and, as such, offers a valuable contribution to delivering a sustainable future [66]. Simulations under a high (slightly below the current emissions trajectory) and low emissions scenario suggested it is plausible for industry to plan for increases in yields in the medium term (2050), although previous studies caution that risks of negative impacts increase in the longer term (2070) [12] [13]. There was considerable agreement between models on the sign of the change however there was evidence for large variability in the magnitude of change between downscaled GCMs. This is important to note in the case of the NSW region, which had the highest simulated increases but also the greatest between model variability. The demand for net irrigation decreased when $\mathrm{CO}_{2}$ levels were elevated, especially for the Burdekin and followed by Mackay and to a lesser extent NSW.

Rötter et al. [67] mention that crop models have been designed to simulate yields at the plot as opposed to the regional level and lack important details about the interaction between carbon dioxide and productivity. The authors warn about the dangers of working with a single "best” model and urge climate-crop modellers to provide bounds of uncertainty on their projection to better inform policy makers. This paper implemented a dual ensemble methodology to cater for the eleven climate models and multiple crop model parameterisations required to capture the complex interactions between the crop's management and environment. The crop ensemble model also factored a calibration that translated simulated potential yields to actual yields. We addressed the need for decision makers to have a level of certainty on which to base their decisions by providing confidence intervals on yield projections from different downscaled GCMs. In recognition of the need to improve the way crop models handle elevated $\mathrm{CO}_{2}$ levels [10] [68], our modelling approach adjusted the stomatal resistance rather than adjusting transpiration or transpiration efficiency directly.

Our research dealt mainly with impacts as opposed to adaptation, with the exception of the implicit management adjustments in irrigation. The impacts identified serve as the basis for some initial discussion of potential adaptation strategies that could simultaneously capitalise on benefits in the short term and prepare for longerterm challenges around greater water demand/deficit. Although this study focused on sugarcane production systems in eastern Australia, the modelling framework can easily be extended to sugarcane and other agricultural production systems around the world.

\section{Acknowledgements}

The Authors would like to thank Yang Wang and Alex Evans for their help with data acquisition. Thanks are also extended to Rodney Neilson, John Markley, Paul Brown and Ben Mayo for help with identification of sugar-growing regions and to Jasmine Jaffrés for her assistance with the manuscript preparation. We acknowledge the international modelling groups for providing their data for analysis, the Program for Climate Model Diagnosis and Intercomparison (PCMDI) for collecting and archiving the model data, the JSC/CLIVAR Working Group on Coupled Modelling (WGCM) and their Coupled Model Intercomparison Project (CMIP) and Climate Simulation Panel for organizing the model data analysis activity, and the IPCC WG1 TSU for technical support. The IPCC Data Archive at Lawrence Livermore National Laboratory is supported by the Office of Science, U.S. Department of Energy. The research was funded by the Australian Government as an SRDC grant (JCU032).

\section{References}

[1] Brumbley, S.M., Snyman, S.J., Gnanasambandam, A., Joyce, P., Herman, S.R., da Silva, J.A.G., McQualter, R.B., Wang, M., Egan, B.T. and Patterson, A.H. (2008) Sugarcane. In: Kole, C. and Hall, T.C., Eds., Compendium of Transgenic Crop Plants: Transgenic Sugar, Tuber and Fiber Crops, Blackwell Publishing Ltd., Oxford.

[2] Alonso-Pippo, W., Luengo, C.A., Koehlinger, J., Garzone, P. and Cornacchia, G. (2008) Sugarcane Energy Use: The Cuban Case. Energy Policy, 36, 2163-2181. http://dx.doi.org/10.1016/j.enpol.2008.02.025 
[3] Barnes, A.C. (1974) The Sugar Cane. Halsted Press.

[4] Goldemberg, J., Coelho, S.T. and Guardabassi, P. (2008) The Sustainability of Ethanol Production from Sugarcane. Energy Policy, 36, 2086-2097. http://dx.doi.org/10.1016/j.enpol.2008.02.028

[5] Mackintosh, D. (2000) Sugar Milling. In: Hogarth, D.M. and Allsopp, P.G., Eds., Manual of Canegrowing, Bureau of Sugar Experiment Stations, Brisbane, 369-377.

[6] Jones, J.W., Hoogenboom, G., Porter, C.H., Boote, K.J., Batchelor, W.D., Hunt, L.A., Wilkens, P.W., Singh, U., Gijsman, A.J. and Ritchie, J.T. (2003) The DSSAT Cropping System Model. European Journal of Agronomy, 18, 235265. http://dx.doi.org/10.1016/S1161-0301(02)00107-7

[7] Keating, B.A., Robertson, M.J., Muchow, R.C. and Huth, N.I. (1999) Modelling Sugarcane Production Systems I. Development and Performance of the Sugarcane Module. Field Crops Research, 61, 253-271. http://dx.doi.org/10.1016/S0378-4290(98)00167-1

[8] Knox, J.W., Rodríguez Díaz, J.A., Nixon, D.J. and Mkhwanazi, M. (2010) A Preliminary Assessment of Climate Change Impacts on Sugarcane in Swaziland. Agricultural Systems, 103, 63-72. http://dx.doi.org/10.1016/j.agsy.2009.09.002

[9] Marin, F.R., Jones, J.W., Singels, A., Royce, F., Assad, E.D., Pellegrino, G.Q. and Justino, F. (2013) Climate Change Impacts on Sugarcane Attainable Yield in Southern Brazil. Climate Change, 117, 227-239. http://dx.doi.org/10.1007/s10584-012-0561-y

[10] Singels, A., Jones M., Marin F., Ruane, A.C. and Thorburn, P. (2014) Predicting Climate Change Impacts on Sugarcane Production at Sites in Australia, Brazil and South African Using the Canegro Model. Sugar Tech, 16, 347-355. http://dx.doi.org/10.1007/s12355-013-0274-1

[11] Biggs, J.S., Thorburn, P.J., Crimp, S., Masters, B. and Attard, S.J. (2013) Interactions between Climate Change and Sugarcane Management Systems for Improving Water Quality Leaving Farms in the Mackay Whitsunday Region, Australia. Agriculture, Ecosystems \& Environments, 180, 79-89. http://dx.doi.org/10.1016/j.agee.2011.11.005

[12] Park, S., Creighton, C. and Howden, M. (2007) Climate Change and the Australian Sugar Industry, Impacts, Adaptation and R\&D Opportunities. SRDC Technical Report. Sugar Research and Development Corporation, Brisbane.

[13] Webster, A.J., Thorburn, P.J., Roebeling, P.C., Horan, H.L. and Biggs, J.S. (2009) The Expected Impact of Climate Change on Nitrogen Losses from Wet Tropical Sugarcane Production in the Great Barrier Reef Region. Marine \& Freshwater Research, 60, 1159-1164. http://dx.doi.org/10.1071/MF08348

[14] Cai, W., Crimp, S., Jones, R., McInnes, K., Durack, P., Cechet, B., Bathols, J. and Wilkinson, S. (2005) Climate Change in Queensland Under Enhanced Greenhouse Conditions. Report 2004-2005. CSIRO Marine and Atmospheric Research, Melbourne.

[15] Santos, D. and Sentelhas, P. (2014) Climate Change Scenarios and Their Impact on Water Balance and Sugarcane Yield in Southern Brazil. Sugar Tech, 16, 356-365. http://dx.doi.org/10.1007/s12355-013-0293-y

[16] Doorenbos, J. and Kassam, A.H. (1979) Yield Response to Water. FAO Irrigation and Drainage Paper No. 33. Food and Agriculture Organization of the United Nations, Rome.

[17] Hastie, T., Tibshirani, R. and Friedman, J. (2001) The Elements of Statistical Learning: Data Mining, Inference and Prediction. Springer, New York. http://dx.doi.org/10.1007/978-0-387-21606-5

[18] Jones, D.A., Wang, W. and Fawcett, R. (2009) High-Quality Spatial Climate Data-Sets for Australia. Australian Meteorological and Oceanographic Journal, 58, 233-248.

[19] R Core Team (2013) R: A Language and Environment for Statistical Computing. R Foundation for Statistical Computing, Vienna.

[20] Liu, D.L. and Scott, B.J. (2001) Estimation of Solar Radiation in Australia from Rainfall and Temperature Observations. Agriculture and Forest Meteorology, 106, 41-59. http://dx.doi.org/10.1016/S0168-1923(00)00173-8

[21] Meehl, G.A., Covey, C., Delworth, T., Latif, M., McAvaney, B., Mitchell, J.F.B., Stouffer, R.J. and Taylor, K.E. (2007) The WCRP CMIP3 Multi-Model Dataset: A New Era in Climate Change Research. Bulletin of the American Meteorological Society, 88, 1383-1394. http://dx.doi.org/10.1175/BAMS-88-9-1383

[22] PCMDI (2002) 20th Century Climate in Coupled Models: A CMIP Pilot Project.

[23] Nakicenovic, N. and Swart, R. (2000) Special Report on Emissions Scenarios: A Special Report of Working Group III of the International Panel on Climate Change. Cambridge University Press, Cambridge.

[24] Timbal, B., Wang, Y. and Evans, A. (2011) Downscaling Climate Change Information: An Essential Ingredient to Incorporate Uncertainties into Adaptation Policies. Proceedings of the 19th International Congress on Modelling and Simulation (MODSIM2011), Perth, 12 to 16 December 2011, 1652-1658.

[25] Timbal, B., Fernandez, E. and Li, Z. (2009) Generalization of a Statistical Downscaling Model to Provide Local Climate 
Change Projections for Australia. Environmental Modelling \& Software, 24, 341-358. http://dx.doi.org/10.1016/j.envsoft.2008.07.007

[26] Bari, M.A., Amirthanathan, G.E. and Timbal, B. (2010) Climate Change and Long Term Water Availability in Western Australia-An Experimental Projection. Proceedings of the 2010 International Congress on Environmental Modelling and Software, Ottawa, 5-8 July 2010, 180-188.

[27] Liu, D.L., Timbal, B., Mo, J. and Fairweather, H. (2011) A GIS-Based Climate Change Adaptation Strategy Tool. International Journal of Climate Change Strategies and Management, 3, 140-155. http://dx.doi.org/10.1108/17568691111128986

[28] Teng, J., Chiew, F.H.S., Timbal, B., Wang, Y., Vaze, J. and Wang, B. (2012) Assessment of an Analogue Downscaling Method for Modelling Climate Change Impacts on Runoff. Journal of Hydrology, 472-473, 111-125. http://dx.doi.org/10.1016/j.jhydrol.2012.09.024

[29] IPCC (2001) Climate Change 2001: The Scientific Basis. In: Houghton, J.T., et al., Eds., Contribution of Working Group I to the Third Assessment Report of the Intergovernmental Panel on Climate Change, Cambridge University Press, Cambridge, $881 \mathrm{p}$.

[30] Tebaldi, C. and Lobell, D. (2008) Towards Probabilistic Projections of Climate Change Impacts on Global Crop Yields. Geophysical Research Letters, 35, L08705. http://dx.doi.org/10.1029/2008gl033423

[31] Semenov, M.A. and Stratonovitch, P. (2010) Use of Multi-Model Ensembles from Global Climate Models for Assessment of Climate Change Impacts. Climate Research, 41, 1-14. http://dx.doi.org/10.3354/cr00836

[32] Armour, J., Nelson, P., Daniells, J., Rasiah, V. and Inman-Bamber, N. (2012) Nitrogen Leaching From the Root Zone of Sugarcane and Bananas in the Humid Tropics of Australia. Agriculture, Ecosystems and Environment, 180, 68-78. http://dx.doi.org/10.1016/j.agee.2012.05.007

[33] Inman-Bamber, N.G. and McGlinchey, M.G. (2003) Crop Coefficients and Water-Use Estimates for Sugarcane Based on Long-Term Bowen Ratio Energy Balance Measurements. Field Crops Research, 83, 125-138. http://dx.doi.org/10.1016/S0378-4290(03)00069-8

[34] Inman-Bamber, N.G., Attard, S.J., Verrall, S.A., Webb, W.A. and Baillie, C. (2007) A Web-Based System for Scheduling Irrigation in Sugarcane. Proceedings of the 2007 International Society of Sugar Cane Technologists Congress, Durban, 29 July-2 August 2007, 459-464.

[35] Inman-Bamber, N.G., Culverwell, T.L. and McGlinchey, M.G. (1993) Predicting Yield Responses to Irrigation of Sugar Cane from a Growth Model and Field Records. Proceedings of the South African Sugar Technologists' Association, 67, 66-72.

[36] Inman-Bamber, N.G. (1991) A Growth Model for Sugar-Cane Based on a Simple Carbon Balance and the CERESMaize Water Balance. South African Journal of Plant Soil, 8, 93-99.

[37] Singels, A., van den Berg, M., Smit, M.A., Jones, M.R. and van Antwerpen, R. (2010) Modelling Water Uptake, Growth and Sucrose Accumulation of Sugarcane Subjected to Water Stress. Field Crops Research, 117, 59-69. http://dx.doi.org/10.1016/j.fcr.2010.02.003

[38] Inman-Bamber, N.G., Attard, S.J. and Spillman, M.F. (2004) Can Lodging Be Controlled through Irrigation? Proceedings of the 2004 Conference of the Australian Society of Sugar Cane Technologists, Queensland, 4-7 May 2004, 1-11.

[39] Singels, A. and Bezuidenhout, C.N. (2002) A New Method of Simulating Dry Matter Partitioning in the Canegro Sugarcane Model. Field Crops Research, 78, 151-164. http://dx.doi.org/10.1016/S0378-4290(02)00118-1

[40] Thorburn, P.T., Biggs, J.S., MacDonald, B.C.T., Allen, D.E. and Denmead, O.T. (2013) What Causes Nitrous Oxide Emissions from Some Sugarcane Crops to Be So High? Proceedings of the Australian Society of Sugar Cane Technologists, Townsville, 16-18 April 2013.

[41] Inman-Bamber, N.G., Zund, P.R. and Muchow, R.C. (2000) Water Use Efficiency and Soil Water Availability for Sugarcane. Proceedings of the Australian Society of Sugar Cane Technologists, 22, 264-269.

[42] Robertson, M.J., Wood, A.W. and Muchow, R.C. (1996) Growth of Sugarcane under High Input Conditions in Tropical Australia. I. Radiation Use, Biomass Accumulation and Partitioning. Field Crops Research, 48, 11-25. http://dx.doi.org/10.1016/0378-4290(96)00041-X

[43] Inman-Bamber, N.G., Everingham, Y. and Muchow, R. (2001) Modelling Water Stress Response in Sugarcane: Validation and Application of the Apsim-Sugarcane Model. Proceedings of the 10th Australian Agronomy Conference, Hobartn, 28 January to 1 February 2001.

[44] Attard, S. and Inman-Bamber, N. (2011) Irrigation Scheduling in the Central Region: Making Every Drop Count. Proceedings of the Australian Society of Sugar Cane Technologists, Mackay, 4-6 May 2011.

[45] Basnayake, J., Jackson, P., Inman-Bamber, N.G. and Lakshmanan, P. (2012) Sugarcane for Water-Limited Environments: Genetic Variation in Cane Yield and Sugar Content in Response to Water Stress. Journal of Experimental Botany, 63, 6023-6033. http://dx.doi.org/10.1093/jxb/ers251 
[46] Sexton, J., Basnayake, J., Everingham, Y., Inman-Bamber, G., Lakshmanan, P. and Jackson, P. (2014) Detailed Trait Characterisation Is Needed for Simulation of Cultivar Responses to Water Stress. Proceedings of the 36th Conference of the Australian Society of Sugar Cane Technologists, Gold Coast, 29 April-1 May 2014, 82-92.

[47] Challinor, A.J., Smith, M.S. and Thornton, P. (2013) Use of Agro-Climate Ensembles for Quantifying Uncertainty and Informing Adaptation. Agricultural \& Forest Meteorology, 170, 2-7. http://dx.doi.org/10.1016/j.agrformet.2012.09.007

[48] Everingham, Y.L., Smyth, C.W. and Inman-Bamber, N.G. (2009) Ensemble Data Mining Approaches to Forecast Regional Sugarcane Crop Production. Agricultural \& Forest Meteorology, 149, 689-696. http://dx.doi.org/10.1016/j.agrformet.2008.10.018

[49] Iizumi, T., Yokozawa, M. and Nishimori, M. (2009) Parameter Estimation and Uncertainty Analysis of a Large-Scale Crop Model for Paddy Rice: Application of a Bayesian Approach. Agricultural \& Forest Meteorology, 149, 333-348. http://dx.doi.org/10.1016/j.agrformet.2008.08.015

[50] Murphy, J.M., Sexton, D.M.H., Barnett, D.N., Jones, G.S., Webb, M.J., Collins, M. and Stainforth, D.A. (2004) Quantification of Modelling Uncertainties in a Large Ensemble of Climate Change Simulations. Nature, 430, 768-772. http://dx.doi.org/10.1038/nature02771

[51] Tao, F. and Zhang, Z. (2013) Climate Change, Wheat Productivity and Water Use in the North China Plain: A New Super-Ensemble-Based Probabilistic Projection. Agricultural \& Forest Meteorology, 170, 146-165. http://dx.doi.org/10.1016/j.agrformet.2011.10.003

[52] Tao, F., Zhang, Z., Liu, J. and Yokozawa, M. (2009) Modelling the Impacts of Weather and Climate Variability on Crop Productivity over a Large Area: A New Super-Ensemble-Based Probabilistic Projection. Agricultural \& Forest Meteorology, 149, 1266-1278. http://dx.doi.org/10.1016/j.agrformet.2009.02.015

[53] Breiman, L. (2001) Random Forests. Machine Learning, 45, 5-32. http://dx.doi.org/10.1023/A:1010933404324

[54] Krogh, A. and Vedelsby, J. (1995) Neural Network Ensembles, Cross Validation, and Active Learning. In: Tesauro, G., Tourestzky, D.S., Leen, T.K., Eds., Advances in Neural Information Processing Systems, MIT Press, Cambridge, 231238.

[55] Friedman, J.H. and Popescu, B.E. (2003) Importance Sampled Learning Ensembles. Department of Statistics, Stanford University, Stanford.

[56] Masson, D. and Knutti, R. (2011) Climate Model Genealogy. Geophysical Research Letters, 38, L08703. http://dx.doi.org/10.1029/2011gl046864

[57] Power, S.B., Delage, F., Colman, R. and Moise, A. (2011) Consensus on Twenty-First-Century Rainfall Projections in Climate Models More Widespread than Previously Thought. Journal of Climatology, 25, 3792-3809. http://dx.doi.org/10.1175/JCLI-D-11-00354.1

[58] Sexton, J., Everingham, Y. and Timbal, B. (2015) Harvest Projections for the Australian Sugar Industry. International Journal of Climate Change Strategies and Management, 7, 41-57. http://dx.doi.org/10.1108/IJCCSM-03-2013-0018

[59] Everingham, Y.L., Stoeckl, N.E., Cusack, J. and Osborne, J.A. (2011) Quantifying the Benefits of a Long-Lead ENSO Prediction Model to Enhance Harvest Management-A Case Study for the Herbert Sugarcane Growing Region, Australia. International Journal of Climatology, 32, 1069-1076. http://dx.doi.org/10.1002/joc.2333

[60] Good, P.I. (1997) Permutation Tests: A Practical Guide to Resampling Methods for Testing Hypotheses. SpringerVerlag, New York.

[61] Everingham, Y., Sexton, J. and Timbal, B. (2013) Downscaled Rainfall Projections for the Burdekin, Mackay and NSW. Proceedings of the 35th Conference of the Australian Society of Sugar Cane Technologists, 16-18 April 2013, Townsville, 1-10.

[62] Inman-Bamber, N.G. (2007) Economic Impact of Water Stress on Sugar Production in Australia. Proceedings of the 2007 Conference of the Australian Society of Sugar Cane Technologists, Cairns, 8-11 May 2007, 167-175.

[63] Park, S., Crimp, S., Inman-Bamber, N.G. and Everingham, Y. (2010) Sugarcane. In: Stokes, C., Howden, M., Eds., Adapting Agriculture to Climate Change, CSIRO Publishing, Collingwood, 85-99.

[64] Stokes, C.J. and Howden, M. (2010) Adapting Agriculture to Climate Change: Preparing Australian Agriculture, Forestry and Fisheries for the Future. CSIRO Publishing, Collingwood.

[65] Jakku, E., Thorburn, P., Everingham, Y. and Inman-Bamber, G. (2007) Improving the Participatory Development of Decision Support Systems for the Australia Sugar Industry. Proceedings of the 2007 Conference of the Australian Society of Sugar Cane Technologists, Cairns, 8-11 May 2007, 41-49.

[66] Skocaj, D., Everingham, Y. and Schroeder, B. (2013) Nitrogen Management Guidelines for Sugarcane Production in Australia-Can These Be Modified for Wet Tropical Conditions Using Seasonal Climate Forecasting? Springer Science Reviews, 1, 51-71. http://dx.doi.org/10.1007/s40362-013-0004-9 
[67] Rötter, R.P., Carter, T.R., Olesen, J.E. and Porter, J.R. (2011) Crop-Climate Models Need an Overhaul. Nature Climate Change, 1, 175-177. http://dx.doi.org/10.1038/nclimate1152

[68] Marin, F.R., Ribeiro, R.V. and Marchiori, E.R. (2014) How Can Crop Modelling and Plant Physiology Help to Understand the Plant Response to Climate Change? A Case Study with Sugarcane. Theoretical and Experimental Plant Physiology, 26, 49-63. http://dx.doi.org/10.1007/s40626-014-0006-2 